\title{
CIDADES DE PEQUENO PORTE E COMANDO DO AGRONEGÓCIO COOPERATIVO NO OESTE PARANAENSE
}

Marcos Xavier ${ }^{1}$

Resumo: A forma como as empresas utilizam o território, definindo as localizações das diferentes etapas da produção e seus fluxos materiais e imateriais, pode revelar as interações entre os lugares e as funções de cada um na divisão territorial do trabalho. O processo produtivo repartido no espaço acaba gerando novas hierarquias entre os lugares utilizados por elas para comandar, controlar e organizar e aqueles destinados a executar as diferentes parcelas da produção. No Oeste Paranaense, o uso do território pelo agronegócio cooperativo tem levado cidades de pequeno porte a se tornarem nós de complexos processos de produção e sedes de decisões corporativas, expandindo e tornando mais complexas a rede de relações estabelecida entre elas e o campo e entre elas as demais cidades do país.

Palavras-chave: Cidades do Agronegócio; Regiões Produtivas Agrícolas; Cooperativas Agroindustriais; Oeste Paranaense

\section{SMALL TOWNS AND COOPERATIVE AGRIBUSINESS COMMAND IN THE WEST OF PARANA}

Abstract: The way companies use the territory, defining the locations of the different stages of production and their material and immaterial flows, can reveal the interactions between the places and the functions of each one in the territorial division of labor. The productive process distributed in the space ends up generating new hierarchies between the places used by them to command, control and organize and those destined to execute the different portions of production. In the West of Paraná, the use of the territory by the agroindustrial cooperative has led small cities to become knots of complex processes of production and headquarters of corporate decisions, expanding and making more complex the network of relations established between them and the Field and among them the other cities of the country.

Keywords: Agribusiness Cities; Agribusiness Region; Agroindustrial Cooperatives; West of Parana

\section{CIUDADES DE PEQUEÑO PORTE Y COMANDO DEL AGRONEGOCIO COOPERATIVO EN EL OESTE PARANAENSE}

Resumen: La forma en que las empresas utilizan el territorio, definiendo las ubicaciones de las diferentes etapas de la producción y sus flujos materiales e inmateriales, puede revelar las interacciones entre los lugares y las funciones de cada uno en la división territorial del trabajo. El proceso productivo repartido en el espacio acaba generando nuevas jerarquías entre los lugares utilizados por ellas para comandar, controlar y organizar y aquellos destinados a ejecutar las diferentes parcelas de la producción. En el Oeste Paranaense, el uso del territorio

1 Professor do Instituto das Cidades da Universidade Federal de São Paulo - Unifesp. E-mail: marcosmoraesxavier@gmail.com 
por el agronegocio cooperativo ha llevado a pequeñas ciudades a convertirse en nodos de complejos procesos de producción y sedes de decisiones corporativas, expandiendo y haciendo más complejas la red de relaciones establecidas entre ellas y el campo y entre ellas las demás ciudades del país

Palabras clave: Ciudades del Agronegocio; Regiones Productivas Agrícolas; Cooperativas Agroindustriales; Oeste Paranaense

\section{INTRODUÇÃO}

Desde a segunda metade do século XX, a expansão da ocupação, da modernização e da urbanização do território brasileiro vem acompanhando o aprofundamento do processo de regionalização resultante da constituição de novas situações geográficas. Estas situações geográficas correspondendo as formas como cada lugar concretiza o que o mundo apresenta como possibilidade (SILVEIRA, 1999), conforme uma combinação única e inédita, num dado momento e num dado subespaço (CATAIA e RIBEIRO, 2015, p.18), das forças de produção, capitais e circunstâncias, como resultado material da história e condição de vida dos indivíduos (MARX e ENGELS, 2007, p. 62).

No atual período, o Estado e as grandes empresas são os principais responsáveis pelos usos do território que engendram estas situações geográficas, subordinando ou inviabilizando outros usos e colocando os interesses e necessidades das populações em segundo plano. Estes usos associados ao empenho de tornar as atividades capitalistas mais eficazes e rentáveis, realizam uma aplicação seletiva de capital, ciência, tecnologia e informação no processo de produção, segundo uma divisão territorial do trabalho na qual certos lugares são escolhidos para abrigar as diferentes etapas produtivas mais ou menos modernas enquanto outros são escolhidos para abrigar o planejamento, o controle e comando do processo produtivo.

Para abordar a singularização dos lugares como resultado da divisão territorial e internacional do trabalho, consideramos ser necessária a identificação das funções que cada um deles cumpre no contexto da formação socioespacial a qual pertencem. Compreendemos que esta tarefa pode ser empenhada dedicando-se à análise das topologias e dos circuitos espaciais de produção e círculos espaciais de cooperação ${ }^{2}$ das empresas capazes de exercer importante força política na organização do território.

Entre as situações geográficas possíveis de serem analisadas, as regiões dedicadas ao

\footnotetext{
2 “Podemos dizer que os circuitos espaciais de produção pressupõem a circulação de matéria (fluxos materiais) no encadeamento das instâncias geograficamente separadas da produção, distribuição, troca e consumo, de um determinado produto, num movimento permanente; os círculos de cooperação no espaço, por sua vez, tratam da comunicação, consubstanciada na transferência de capitais, ordens, informação (fluxos imateriais), garantindo níveis de organização necessários para articular lugares e agentes dispersos geograficamente." (CASTILLO e FREDERICO, 2010, p. 464)
} 
agronegócio se apresentam como interessantes amostras do atual uso seletivo e hierárquico do território brasileiro, pois envolvem a modernização do campo e a urbanização da sociedade e do território decorrente do avanço das atividades capitalistas no interior do país. Regiões nas quais tem sido engendrado um novo Brasil urbano não metropolitano (ELIAS, 2008) que necessita ser compreendido.

Propomos aqui uma reflexão sobre a particularidade das cidades de pequeno porte do Oeste Paranaense que, além de abrigarem as atividades de produção, comércio e serviços associadas à agricultura e a pecuária globalizadas, também se destacam por serem sedes das cooperativas agroindustriais regionais, o que traz novos elementos para as interações geográficas e a hierarquização dos lugares.

Iniciamos a discussão abordando a pertinência de tratar as cidades de pequeno porte no seio das relações interurbanas do presente, observando um recorte analítico específico: os fluxos materiais e imateriais que chegam e saem delas, associados ao processo de produção. $\mathrm{Na}$ sequência, realizamos uma breve apresentação do Oeste Paranaense, região produtiva agrícola especializada na cadeia produtiva de proteína, na qual as cooperativas agroindustriais atuam destacadamente na produção e na política. Considerando que a importância de cada cidade é sempre relativa e contingente, resultando dos impulsos externos e internos da rede urbana que encontram nela uma resposta localizada (SANTOS, 1996b, p. 81), finalizamos este artigo discutindo como, ao dar abrigo às sedes das cooperativas do agronegócio e participando de interações de amplo alcance, cidades de pequeno porte no Oeste Paranaense nos apresentam indícios de assumirem funções de cidades intermediárias.

\section{Cidades de pequeno porte, funções e relações: questões do presente}

Observando a abundância de pesquisas sobre as metrópoles, geógrafos como Milton Santos, Roberto Lobato Corrêa e Tânia Fresca (SANTOS, 2005 [1972], p.85; CORRÊA, 1999; FRESCA, 2001, p.28) alertaram para a necessidade de também se estudar as pequenas cidades para que possamos compreender a urbanização brasileira diante do processo de globalização. Segundo Tânia Fresca (idem), a partir dos anos 1990 estas cidades passaram a ser mais consideradas nos estudos urbanos (ver OLIVEIRA e SOARES, 2002; MELO e SOARES, 2009; OLANDA, 2008, ENDLICH, 2011, SPOSITO, 2010); o que, para a mesma autora (FRESCA, 2010, p. 75), é uma consequência da observação da imposição de novas demandas para essas cidades, decorrente da intensificação da reestruturação produtiva, possibilitando a elas o desempenho de novas centralidades no contexto das redes urbanas. 
Dinamismo que revela a pertinência de se dedicar à compreensão dessas cidades situadas fora do contexto metropolitano.

$\mathrm{O}$ tratamento das pequenas cidades encontra de imediato o problema dos critérios utilizados para sua definição. Autor de referência em estudos urbanos, Roberto Lobato Corrêa, por exemplo, considerando o tamanho populacional, ora define estas cidades como aquelas inferiores a 50 mil habitantes (CORRÊA, 1999, p, 48), ora como aquelas que dificilmente ultrapassam 20 ou 30 mil habitantes (CORRÊA, 2011, p. 7). Já Edson Rodrigues Olanda (OLANDA, 2008, p. 184), ao analisar o estado de Goiás, entende como pequenas aquelas cidades inferiores a 20 mil habitantes.

Mesmo considerando que o tamanho da cidade é relacionado ao período histórico e ao contexto regional no qual ela está localizada, o problema é de complicada resolução. Como observa Tânia Fresca (FRESCA, 2011, p. 76) "utilizando-se este caminho para caracterizar uma cidade como sendo pequena, incorre-se no risco de igualar cidades que na sua essência são diferentes". Não é suficiente afirmar que atualmente uma cidade de 25 mil habitantes pode ser pequena no interior paulista, em decorrência da dimensão e complexidade da rede urbana regional, enquanto outra, com o mesmo número, não o é no seio da região Amazônica ou no interior do Nordeste.

Milton Santos, conhecendo os limites das classificações quantitativas, preferiu trabalhar com a noção de cidade local (SANTOS, 2005 [1972]), adotando um ponto de vista funcional e qualitativo. Segundo sua proposta, "a cidade local é a dimensão mínima a partir da qual as aglomerações deixam de servir às necessidades da atividade primária para servir às necessidades inadiáveis da população, com verdadeira especialização do espaço”. (SANTOS, 2005 [1972], p. 87). Trata-se, portanto, “da cidade capaz de responder às necessidades vitais mínimas de toda uma população, o que pressupõe uma vida de relações” (idem, p. 88). Para ele, é o consumo regular de bens e serviços da população urbana, mas também da população residente nas zonas de produção primária que as definem como cidades.

Mais tarde, o mesmo autor (SANTOS, 2005 [1989], p.127) irá propor que a cidade local corresponderia àquela que, diante da modernização da agricultura, tornar-se-ia responsável por assegurar a cooperação imposta pela nova divisão do trabalho agrícola, afeiçoando-se ao campo e respondendo às suas demandas. Elas deixam de ser cidades no campo para se tornarem cidades do campo. Cidades que regulam o que se faz no campo, assegurando a cooperação decorrente da nova divisão do trabalho agrícola. Ele observa que a presença cada vez maior da agroindústria amplia a importância dessas cidades, na medida em que elas possibilitam o consumo produtivo gerador de muitas trocas realizadas entre os 
lugares da produção agrícola e os centros urbanos.

Roberto Lobato Corrêa (CORRÊA, 2011), considerando as profundas transformações associadas à modernização do campo e ao processo de industrialização, pelos quais o Brasil passou a partir da segunda metade do século XX, propõe cinco tipos ideais de pequenas cidades, que considera não ultrapassarem 30 mil habitantes: os centros locais, os centros especializados, os reservatórios de força de trabalho, centros decadentes que vivem de recursos externos e os subúrbios dormitórios. Para os fins analíticos aqui propostos, iremos expor apenas o que o autor entende ser as pequenas cidades do tipo centros locais.

Para Corrêa, com base no modelo dos lugares centrais de Christaller, os centros locais correspondem às pequenas cidades localizadas nas áreas agrícolas modernas. Cidades que estão situadas na confluência do agrário moderno com o urbano. Para ele (CORRÊA, idem, p. 11), "trata-se, conforme sugerido por Milton Santos, da cidade do campo, lugar central de uma hinterlândia agrária moderna, capitalista”.

Na perspectiva de Tânia Fresca, centros locais e pequenas cidades, no entanto, não são sinônimos. Segundo a autora (FRESCA, 2010, p. 77), o centro ou cidade local, refere-se ao menor escalão das cidades no Brasil, aquele núcleo urbano cuja oferta de bens e serviços é capaz de atender às necessidades vitais mínimas de uma população. Concordando com Milton Santos, Fresca considera tratar do menor nível hierárquico de uma rede de lugares centrais abaixo do qual "pode haver aglomeração, mas jamais uma cidade (SANTOS, 2005 [1972], p. 88). Essa autora observa que certas cidades podem apresentar uma maior complexidade de atividades urbanas que extrapolam estas necessidades mínimas de sua população e hinterlândia se inserindo de maneira mais complexa na rede urbana e, desta forma, deixando de ser centros locais, o que, segundo ela, justificaria o uso da expressão pequena cidade para defini-las. A autora utiliza o próprio conceito de cidade do campo de Milton Santos para justificar sua proposição.

Segundo seu entendimento, na medida em que as cidades do campo incorporam atividades mais complexas associadas às modernas produções agrícolas, suas dimensões físico territoriais, populacionais e da parcela da mais valia que controlam são superiores àquelas da cidade local. Na medida em que estas cidades do campo passam a atender as necessidades de produções particulares como soja, trigo ou milho, assumem funções especializadas, inclusive industriais, tornando-se diferenciadas umas das outras, sendo inseridas em novas articulações regionais, nacionais e internacionais.

Mesmo quando Milton Santos, Roberto Lobato Corrêa e Tânia Fresca chamam a atenção para o fato de a questão central ser a forma como as cidades se inserem na rede 
urbana, observamos ser difícil escapar da consideração do tamanho populacional das cidades. Mas estamos de acordo que esse é o caminho mais seguro se quisermos compreender as diferentes feições da urbanização brasileira, pois entendemos que, neste caso, o objeto de estudo não é exatamente a cidade, mas o sistema de relações do qual participa (ROCHEFORT, p.3, 1961), ou seja, as relações cidade e campo e a rede urbana.

Maurício de Abreu, ao abordar a história dos estudos geográficos da cidade no Brasil, observou que, no início do século XX, ainda não havia trabalhos que destacassem as relações entre as cidades (ABREU, 1994). Segundo ele, a geografia urbana, sob influência de Pierre Monbeig, era então embasada na produção de monografias inspiradas no método regional de Vidal de La Blache. Foi a partir dos anos 1950, graças à influência de geógrafos franceses como Jean Tricart e Michel Rochefort e a radical transformação da estrutura espacial dos fixos e fluxos gerados pela dinâmica do capitalismo no país, que os estudos sobre as redes urbanas passaram a se sobressair (ABREU, idem, p.38-39). São exemplos dessa influência, o empenho de Pedro Pinchas Geiger (GEIGER e DAVIDOVICH, 1961) e Milton Santos (SANTOS, 1959) em compreender as redes e hierarquias urbanas brasileiras em um Brasil que começa a conhecer um intenso e acelerado processo de transformação associado à modernização do campo, à industrialização, à urbanização e à integração do território.

Abreu também chama a atenção para o fato de, entre os anos 1960 e 1970, os estudos vinculados à teoria dos lugares centrais de Christaller terem sido propostos para subsidiar as ações do Estado, então empenhado em planejar o desenvolvimento via difusão seletiva das inovações no seio das redes urbanas. Desde então, até nossos dias, diversos estudos geográficos sobre as redes e hierarquias urbanas ainda têm sido significativamente baseados nas perspectivas de Walter Christalller e Michel Rochefort (CORRÊA, 1989; MOURA e WERNECK, 2001; ELIAS, 2008 EGLER et ali, 2011; BESSA, 2012; CONTE, 2014; CANTARIM, 2015;)

A discussão que propomos realizar aqui sobre as cidades de pequeno porte do Oeste Paranaense, toma como partido ser impossível compreendê-las sem considerar as relações que estabelecem com outras cidades brasileiras. No entanto, está distante de tratar a complexidade da rede e hierarquia urbana no atual período, decorrente das atuais condições de realização da vida econômica e social. Temos consciência da envergadura de tal tarefa. Não somos indiferentes ao conselho de Milton Santos (SANTOS, 2005 [1989], p. 128), quando observa que “toda simplificação no tratamento da questão precisa ser superada". Mas com base na análise das ações das cooperativas agroindustriais a partir dessas cidades no Oeste Paranaense, consideramos ser possível responder algumas questões que julgamos pertinentes sobre as 
especificidades da urbanização brasileira.

1 Quais implicações para a urbanização são geradas pela modernização do território com a expansão das forças produtivas e relações de produção características do período técnicocientífico-informacional nas regiões dedicadas à produção agroindustrial?

2 Diante da ampliação das áreas envolvidas no processo produtivo (produção, circulação, distribuição e consumo), caracterizando uma ampliação dos contextos (SANTOS e SILVEIRA, 2001), qual a natureza e o alcance dos fluxos materiais e imateriais estabelecidos a partir das cidades do campo?

3 Que funções as cidades de pequeno porte podem assumir nas regiões agrícolas modernas?

4 A participação em uma complexa teia de relações espacialmente estendida conduziria parcela destas cidades a se constituírem como cidades intermediárias, responsáveis pela interlocução entre os lugares, a totalidade do território e o mundo?

Segundo nosso entendimento, estas são algumas perguntas que a situação analisada neste trabalho nos traz e cujos apontamentos e observações a serem expostos parecem indicar uma maior complexidade relacionada tanto às funções assumidas pelas cidades quanto aos fluxos materiais e imateriais hierarquicamente estabelecidos entre elas.

\section{O Oeste Paranaense: uma região produtiva agrícola}

O Oeste Paranaense (mapa 1) é uma região marcada pelo avanço da ocupação por meio de pequenos produtores agrícolas. No século XIX já tinha recebido colonos alemães que ocuparam parte de suas terras (Ipardes, 2008, p. 13). Mas é nos anos 1930, com a Marcha para o Oeste promovida pelo presidente Getúlio Vargas, que a região será agregada a um movimento mais definido e robusto de ocupação e integração do território, garantindo o povoamento da faixa de fronteira segundo os interesses do Estado e do mercado. Destaca-se nesse processo o papel das companhias gaúchas na exploração de madeira e no loteamento e comercialização de terras, promovendo a chegada de pequenos produtores oriundos do Rio Grande do Sul e de Santa Catarina "atraídos pela possibilidade de construir um futuro mais promissor ou, simplesmente, expulsos pelo processo acumulativo e concentracionista em curso em seus locais origem" (Ipardes, 2008, p. 15). Fato que será de grande relevância para definir a futura estrutura fundiária da região, bem como a valorização da organização cooperativa como estratégia de manutenção de pequenos e médios produtores rurais. 


\section{Mapa 1: Oeste Paranaense}



Esses colonos já saíram de suas regiões de origem com experiência na produção comercial, o que contribuiu para expansão de atividades voltadas a abastecer mercados extra regionais desde o início. Além das companhias de colonização, a implantação de novas infraestruturas como a Ponte da Amizade em 1965, o asfaltamento da rodovia BR-277 em 1969 e o início das obras da usina hidrelétrica de Itaipu nos anos 1970 contribuíram para acelerar e intensificar o processo de ocupação do território e da expansão da produção agropecuária comercial.

A partir dos anos 1970, a modernização agrícola se desenvolve por meio de uma intrínseca relação entre as atividades agropecuárias e a produção agroindustrial com significativa participação do cooperativismo empresarialmente desenvolvido (FARJADO, 2006, p.89; CIRADINI \& FREDERICO, 2009, p. 5) apoiado pelo Estado até os anos 1980. Essa modernização foi favorecida pelo encontro entre a experiência dos produtores rurais no plantio de grãos, as ações do Estado estimuladoras de produções vinculadas às demandas urbanas e às pautas de exportação, a disponibilidade de solos férteis com topografia plana e a aplicação das inovações associadas à Revolução Verde - mecanização, uso de insumos químicos e melhoria genética das espécies.

Destaca-se a integração da região à moderna economia capitalista por meio da 
expansão, tecnificação e mecanização do cultivo de soja (Ipardes, 2008, 16) para atender as demandas da indústria nacional e da produção internacional de ração animal. Exportações que contribuíam com o financiamento dos projetos de desenvolvimento previstos nas ações do I Plano Nacional de Desenvolvimento - I PND (1970-1974) e do II PND (1974-78) (Ipardes, 2008, p. 31). Nesse contexto, o Programa Especial do Oeste do Paraná visou incorporar a região à economia de mercado por meio de investimentos em infraestruturas articulando as frações do capital de materiais, equipamentos e bens finais de consumo (PIQUET, 2007, p. 54).

A partir da última década do século XX, transformações político-econômicas como a maior abertura do mercado, a redução dos investimentos e subsídios estatais, uma nova vaga de inovações tecnológicas e a maior exposição à concorrência levaram as empresas do agronegócio, dentre elas as cooperativas agropecuárias, a intensificaram sua atuação no processamento industrial. As cooperativas diversificaram seus negócios e passaram a desenvolver processos e produtos (FERREIRA e BRAGA, 2004). Se tornaram empresas pivô de redes verticais integradas, articulando fornecedores, distribuidores e clientes corporativos, assegurando o controle estratégico de uma complexa cadeia produtiva (MAZZALI, 2000) que transforma grãos (soja e milho) em produtos elaborados a base de proteína animal (suínos, aves, leite e peixe).

Elas incorporam estratégias competitivas buscando se projetar como players no mercado nacional e internacional. Em detrimento de seu papel social junto aos cooperados, acabam por adotar práticas oligopsônicas junto aos produtores, impondo padrões de qualidade, produtividade e preço tornando seletiva a permanência dos pequenos e médios produtores associados. Desde então, tanto o campo quanto a cidade veem sendo transformados com a adesão de novos sistemas de objetos e sistemas de ações ${ }^{3}$ que amoldam o território às necessidades de ganhos de racionalidade, produtividade e competitividade dessas empresas. $\mathrm{O}$ entrelaçamento entre ciência, técnica e informação, associado à ascensão de um modelo de acumulação centrado na agroindústria faz expandir na região o meio técnico-científico-informacional (SANTOS, 1994a, 1994b, 1996a; SANTOS e SILVEIRA, 2001).

São implantados modernos sistemas de engenharia públicos e privados, como

\footnotetext{
${ }^{3}$ Entre os sistemas de objetos estão incluídos sistemas de transporte, comunicação e energia, silos, armazéns, fábricas, fazendas modernas e insumos agrícolas e industriais. Entre os sistemas de ações estão novas formas de organização da produção, fluxos de informação e dinheiro, normas e atividades produtivas, incluindo comércios e serviços voltados à produção. Em ambos os casos, com crescente conteúdo científico e informacional.
} 
rodovias, silos, armazéns, plantas industriais e infraestrutura de energia e comunicação. O conteúdo normativo do território é intensificado, pois a implantação dos sistemas técnicos produtivos e o uso eficaz dos mesmos são acompanhados pela criação de formas de regulação jurídica, técnica e financeira que incidem sobre a organização da produção. Cresce o número e o tamanho dos núcleos urbanos onde se instalam, além da agroindústria, serviços, comércios e atividades de ensino e pesquisa demandados pelo agronegócio.

Ao mesmo tempo, a estrutura fundiária é modificada com tendente concentração da propriedade, sem, no entanto, diminuir a importância da agricultura familiar que, grosso modo, passa a ser moderna e integrada às redes produtivas do agronegócio. A estrutura do trabalho é modificada comportando uma maior e complexa divisão social e técnica do trabalho, incluindo o trabalhador agrícola não rural e um maior número de variedade de trabalhadores urbanos. O consumo é diversificado e expandido. Aumentam as demandas produtivas do campo, que passa a consumir intensamente insumos e serviços característicos da modernização produtiva. Um indicativo desse consumo é o fato de as cooperativas que analisaremos mais a frente manterem 148 unidades, apenas no Paraná, que comercializam máquinas, equipamentos, sementes, agrotóxicos, produtos veterinários, fertilizantes e rações, prestação de consultoria e assistência técnica agrícola e pecuária, além de serviços contábeis, financeiros e securitários. O consumo das famílias também cresce e se moderniza tanto na cidade quanto no campo. Mesmo nas cidades de menor porte são encontradas lojas de franquias nacionais e internacionais e nas cidades de maior porte grandes cadeias de supermercados e modernos shopping centers. Este consumo resultando do crescimento das classes médias urbanas, que passam a contar com engenheiros agrônomos, administradores, advogados, tecnólogos de solo, geneticistas, veterinários e demais profissionais contratados para interpretar os novos sistemas técnicos (SILVEIRA, 2010, p.80), mas também da renda dos produtores agropecuários gerada pela exploração capitalista da terra atrelada à agroindústria que lhes permite consumirem produtos e serviços urbanos.

A síntese de todas estas mudanças é a transformação do Oeste Paranaense em uma região produtiva agrícola, território do agronegócio globalizado, um híbrido formado por espaços agrícolas e espaços urbanos (ELIAS, 2012 p. 3), onde se destacam as cidades do agronegócio (ELIAS, 2006), onde estão localizados o controle e a organização técnica do trabalho, bem como os comércios, os serviços e as produções demandados pelo circuito superior da economia agrícola. Região alicerçada por imbricadas relações estabelecidas entre cidade e campo com base em elevadas densidades técnica, científica e informacional (SANTOS, 2005 [1989], p. 169). Uma região competitiva, “expressão geográfica da produção 
obediente a parâmetros internacionais de qualidade e custos" (CASTILLO e FREDERICO, 2010, p.18) cujo grau de urbanização salta de 50,4\%, em 1980 para 71,6\% em 1991, chegando em 2010 a 85.6\%. (Ipardes, Base de Dados do Estado, BDEweb).

Dentre os diferentes sujeitos e processos que levam a cabo a consolidação do Oeste Paranaense como uma região produtiva agrícola estão as cooperativas agroindustriais. Assim como o Estado e as grandes empresas privadas que atuam no nessa região, as cooperativas agroindustriais se posicionam como sujeitos efetivos de ações movidas por intenções precisas, planejadas e que visam atingir a um projeto (RIBEIRO, 2014). Agem como atores sintagmáticos (RAFFESTIN, 1993), estabelecendo estratégias territoriais de ação que contribuem para a constituição de arranjos produtivos regionais que territorializam, em espaços contíguos do Oeste Paranaense, parcela significativa de circuitos espaciais de produção e círculos de cooperação mais abrangentes, constituídos por complexas redes produtivas variáveis conforme os diferentes produtos.

No percurso das investigações, observamos que o estreitamento e interdependência das relações estabelecidas entre campo e cidade, agropecuária e indústria, no caso em tela, decorre do fato de todas as cooperativas envolvidas apresentarem um sistema organizacional na forma de integração vertical com significativo grau de diversificação dos negócios, o que inclui a produção e fornecimento de pintainhos, suínos e bezerros, sementes, rações e fertilizantes, assistência técnica, financiamento, controle de qualidade, armazenamento, comercialização, processamento industrial, distribuição, propaganda e marketing, criando uma trama que enreda os produtores rurais que se sujeitam ao controle das cooperativas, garantindo a elas o fornecimento seguro de matéria-prima para processamento.

As cooperativas apresentam um elevado grau de enraizamento no território onde surgiram e atuam e fazem uso de um discurso que busca legitimar suas ações que estariam comprometidas com o desenvolvimento regional. Elas têm de lidar com os desafios de se manterem competitivamente nos mercados e, ao mesmo tempo, garantir certas ações atreladas aos princípios do cooperativismo que objetivam o bem-estar de seus cooperados, mesmo estas ações sendo menos expressivas e até residuais. A título de exemplo, a Lar mantém uma fábrica de fécula de mandioca em Missal pouco significativa em seu leque de negócios, mas considerada importante na história da cooperativa e para a manutenção de parte de seus associados. Um posto de combustível é mantido no pequeno município de Serranópolis do Sul, por ser a única possibilidade para abastecimento dos cooperados ali instalados.

Este entrelaçamento e ancoragem também é observado na estrutura administrativa. Como observa Zybersztajn (1994, p. 30), mesmo diante da profissionalização da gestão, as 
cooperativas continuam sendo administradas por executivos oriundos do quadro de cooperados. Mesmo adquirindo grande porte, elas elegeram certas cidades regionais como centros de gestão. Daí a importância de se compreender o uso que essas cooperativas fazem do território, na medida possuem ampla capacidade de moldá-lo em conformidade com seus interesses estratégicos.

\section{As cidades da gestão do agronegócio}

Tânia Fresca (2011, p. 79), preocupada com os estudos sobre as pequenas cidades, chamou a atenção para a importância de se refletir sobre como elas estabelecem o controle do campo e participam da produção propriamente dita. Propõe a análise dos mecanismos das grandes empresas ou das cooperativas agroindustriais como um caminho para entender estas relações entre as cidades e a produção agropecuária. O levantamento das topologias, dos circuitos espaciais produtivos e dos círculos de cooperação das cooperativas agroindustriais do Oeste Paranaense, vem ao encontro dessa proposição, destacando o controle do processo produtivo exercido por elas a partir das cidades onde estão suas sedes.

No Oeste Paranaense, 9 municípios abrigam sedes administrativas de cooperativas agroindustriais (tabela 1, mapa 2). Dentre estes, segundo dados censitários do IBGE para 2010, apenas Toledo e Cascavel possuem mais de 50 mil habitantes.

Tabela 1-Municípios que sediam cooperativas agroindustriais no Oeste Paranaense - população censitária total, urbana e rural, - 2010

\begin{tabular}{|c|c|c|c|c|}
\hline Mumicípios & Cooperativas & & pulação & \\
\hline & & unbsun & rumal & total \\
\hline Assis Chatesubriand & Agropar & 29.013 & 4.012 & 33025 \\
\hline Cafelândia & Copacol* & 12.348 & 2.314 & 14662 \\
\hline Cascavel & Coopavel, Cotriguaçu, Coocentral & 270.049 & 16.156 & 286205 \\
\hline Marechal Cândido Rondon & Copagril ${ }^{*}$ & 39.147 & 7.672 & 46819 \\
\hline Medianeira & Frimess, Lar & 37,390 & 4,427 & 41817 \\
\hline Nowa Aurora & Coave & 9.040 & 2.826 & 11866 \\
\hline Palotina & C. Vale & 24.646 & 4.037 & 28683 \\
\hline Santa Helena & Coofamel & 12.586 & 10.827 & 23413 \\
\hline Toledo & Primato* ${ }^{*}$ Coovicapar. Coopemobre & 108.259 & 11.054 & 119313 \\
\hline
\end{tabular}

Rontes: Banco de Dados Ipardes - 2018 OCEPAR - 2016, * cooperativas filiadas à Frimesa

Entre as cooperativas elencadas, analisamos a Lar, a Copagril, a C. Vale, a Primato e a Copacol, respectivamente sediadas nos municípios de Medianeira, Marechal Cândido 
Rondon, Palotina, Toledo e Cafelândia, coproprietárias da Frimesa, empresa que se dedica ao processamento de carne suína e a produção de derivados de leite, sediada na cidade de Medianeira. Tal escolha se deve ao fato de cada uma dessas cooperativas apresentar uma divisão territorial do trabalho particular e, ao mesmo tempo, participar de uma imbricada articulação produtiva associada à Frimesa, contribuindo significativamente para o delineamento de arranjos produtivos regionais da produção de proteína. 
Mapa 2. Municípios onde estão as sedes das cooperativas agroindustriais do Oeste Paranaense




A topologia, os circuitos espaciais de produção e os círculos espaciais de cooperação dessas empresas contribuem para revelar as atuais feições da organização produtiva do território, sua compartimentação e urbanização. Como poderá ser observado em seguida, a área de atuação das cooperativas e seus fluxos materiais e imateriais indicam a força que possuem na constituição de regiões produtivas agrícolas e as interações espaciais marcadas pela ampliação dos contextos com a expansão das áreas e do número de lugares envolvidos na produção, distribuição, circulação e consumo.

A Frimesa é uma central cooperativa que possui cinco unidades industriais. Em Medianeira está a planta de processamento de carnes. Em Marechal Cândido Rondon, Matelândia e Capanema, no Paraná, e Aurora, em Santa Catarina, estão as unidades de processamento de leite, abastecidas por postos localizados no Paraná e no Mato Grosso do Sul. Fabrica 370 produtos diferentes e atende, principalmente, o pequeno e médio varejo em todo o território. Também abastece redes de fast food, cozinhas industriais, restaurantes, catering, pizzarias e hotéis. Quando realizamos nossa pesquisa, além de atender o mercado brasileiro, a empresa exportava cortes de carne para Angola, Argentina, Bolívia, Alemanha, Paraguai, Singapura, Tailândia, Uruguai e Hong Kong.

As cooperativas coproprietárias da Central Frimesa dividem o território em áreas delimitadas pelos municípios onde estão instaladas as unidades produtivas de seus cooperados que fornecem carne suína e leite à Frimesa e que também abrangem os processos produtivos particulares de cada uma. Nessas áreas, elas atuam em diferentes setores da produção agroindustrial e controlam grande parte do processo produtivo no campo. Além de abastecer a Frimesa com leite e suínos, as cooperativas Lar, Copacol e Copagril competem no mercado de cortes e processados de aves, a segunda e a terceira também atuando no mercado de peixes.

Todas as cooperativas possuem produtores dedicados à produção de soja, trigo e milho e a pecuária bovina leiteira. No caso dos produtores da Copacol e da Copagril, também são incluídos produtores de peixe. O que faz com que o mesmo produtor seja fornecedor de carne suína e leite à Frimesa e de frango ou peixe às suas respectivas cooperativas. As rações fabricadas pelas cooperativas utilizam a soja e o milho produzidos pelos seus cooperados que, por sua vez, irão consumi-las na produção pecuária. A C.Vale, nos municípios de Abelardo Luz e Faxinal dos Guedes - SC, Clevelândia - PR e Tapera - RS e a Lar em Xanxerê - SC produzem as sementes de soja que são fornecidas aos seus cooperados. Pacotes tecnológicos incluindo insumos, serviços e métodos de produção, padrões de produto e controle de qualidade são determinados pelas cooperativas, bem como a remuneração dos resultados. 
Desta forma, elas atuam de maneira similar às grandes corporações do setor, orquestrando um sistema de alta competitividade mais comprometido com o processo de acumulação do que com a manutenção dos pequenos produtores regionais que podem perder as condições de acompanhar os parâmetros exigidos para a integração.

A divisão territorial do trabalho estruturada pelas cooperativas cria complexos circuitos espaciais de produção e círculos de cooperação que, para fins analíticos, podem ser subdivididos entre dois subsistemas entrelaçados e indissociáveis. No primeiro destacam-se as relações de proximidade. A topologia das sedes administrativas, dos laboratórios, das plantas industriais, fazendas experimentais, silos, armazéns e prestação de serviços aos produtores cooperados criam fixos e fluxos que contribuem para a definição de extensões contíguas articuladas na produção de proteínas nas quais as cooperativas exercem um papel central na definição dos sistemas técnicos e na organização do trabalho, configurando os espaços da solidariedade orgânica da divisão técnica e social do trabalho.

No caso do processamento de carne, destaca-se o imperativo logístico associado à necessidade de proximidade entre a indústria de processamento e os produtores rurais, exigindo um circuito espacial produtivo delimitado pelas condições ótimas de tempo de deslocamento, que implicam diretamente na qualidade dos animais para abate nos frigoríficos. Embora haja significativos avanços na logística refrigerada, o mesmo é valido para o processamento de laticínios que é majoritariamente abastecido por produtores regionais. Já a produção de grãos apresenta uma maior extensão. Além do Oeste Paranaense, as cooperativas possuem centros de recebimento e armazenamento de grãos, unidades de negócios, lojas agrícolas e serviços de assistência técnica nas regiões Sul e Centro-Oeste e também na região do Alto Paraná, no Paraguai. Regiões onde se destacam a atuação da Lar e da C.Vale como tradings responsáveis por grande parte da comercialização da produção regional.

Porém, quando consideramos a topologia e os fluxos materiais e imateriais que envolvem fornecedores de insumos industriais e serviços, os escritórios de vendas, a logística de distribuição e os mercados, ou seja, a totalidade dos circuitos espaciais de produção e dos círculos de cooperação, observamos uma maior extensão do uso do território que estas cooperativas atingem correlatas às solidariedades organizacionais que engendram articulando espaços não contíguos.

As topologias, os circuitos espaciais de produção, os círculos espaciais de cooperação demonstram que as cooperativas são fortemente ancoradas no território que lhe dá abrigo e que elas utilizam como recurso. Esta ancoragem sendo uma decorrência do cooperativismo regional e da interdependência entre a agroindústria e a produção agropecuária de tal forma 
que, como observamos acima, as sedes das cooperativas estão instaladas nas cidades regionais de onde partem fluxos informacionais de decisão, comandos e ordens que implicam em novas funções e hierarquias urbanas.

Segundo Milton Santos, entre os problemas gerais aos quais a geografia pode se ocupar analiticamente no atual período estão às relações cidade-campo (SANTOS, 1994b), dentre as quais destacamos aqui as novas atividades de concepção, comando, administração superior ou controle das atividades agroindustriais modernas. Atividades localizadas nas metrópoles e cidades médias, mas que este mesmo autor põe em questão se não estariam também localizadas em cidades menores (idem, p.132). Vejamos o que a topologia das sedes das cooperativas aqui analisas revela em relação a essa questão.

Aos nossos olhos, a força política e econômica que as cooperativas agroindustriais possuem no Oeste Paranaense, bem como os circuitos espaciais da produção que articulam e seus correlatos círculos de cooperação, contribuem para que as cidades locais que as sediam assumam funções mais complexas na divisão do trabalho. Fato que torna limitante, no atual contexto, compreender as funções e relações dessas cidades apenas com base em suas dimensões populacionais e no alcance da influência dos comércios e serviços públicos e privados que possuem. Roberto Lobato Corrêa (2001, p. 428) já observou que as especializações produtivas que emergem da atual divisão territorial do trabalho conferem às cidades funções e singularidades que as definem melhor.

Como vimos, a gestão dos processos produtivos realizada a partir dessas cidades incide em grandes extensões do Oeste Paraense; inclui porções significativas da Região Concentrada e da Região Centro-Oeste (SANTOS, 1994a; SANTOS e SILVEIRA, 2001). Também incide em território paraguaio, nas regiões que fazem fronteira com o Oeste do Estado do Paraná. A localização das unidades, fábricas, supermercados, escritórios de apoio e serviços, farmácias veterinárias, lojas, escritórios de vendas e centros de distribuição das cooperativas é reveladora do alcance territorial dessas empresas, bem como o alcance territorial dos comandos que são emitidos a partir das cidades onde estão suas sedes. Em termos de mercados, as cooperativas atendem a totalidade do território brasileiro e são responsáveis por importante parcela das exportações de corte de carne, particularmente para mercados europeus e asiáticos, destacando-se a exportação de frango para mercados muçulmanos que exigem o abate halal, conforme preceitos e normas presentes no Alcorão.

Além de atender os padrões culturais de consumo de seus clientes, as empresas também atendem a padrões certificados por selos de qualidade emitidos por agências internacionais, revelando certo grau de alienação do território em razão da adequação da 
estrutura produtiva regional aos ditames dos mercados internacionais, bem como a vulnerabilidade regional em função das variações e idiossincrasias desses mercados. O mapa 3 apresenta abrangência territorial das cooperativas analisadas em conjunto, possibilitando observar a escala de atuação das empresas, suas extensões contíguas e não contíguas sobre as quais incidem as decisões tomadas a partir das cidades onde suas sedes estão localizadas.

Assim como outras empresas competitivas, a partir dos anos 1990 e com maior intensidade ao longo dos anos 2000, as cooperativas agroindustriais do Oeste Paranaense, se inserem no que Antônio Barros de Castro denomina de economia de decisão intensiva, que valoriza o gerenciamento, as escolhas dos consumidores e a participação dos trabalhadores na produção, e de economia de relações intensivas, em que se estabelece uma maior interação das empresas entre si, com os consumidores, universidades e centros de pesquisa (CASTRO e CASTRO, 2012, p. 159). Isto significa que as atividades e fluxos vinculados à informação diretamente relacionados ao processo produtivo, à logística, à gestão e às finanças - adquirem centralidade e imprimem novos conteúdos e significados às cidades que abrigam as sedes das empresas que geram, processam, analisam, interpretam e emitem informação, além de gerarem fluxos de massas que materializam uma circulação de bens em vasta porção do território. As cidades que abrigam as sedes e plantas industriais das cooperativas agroindustriais são inseridas em uma rede de relações urbanas mais complexa, segundo uma hierarquia dos lugares na qual a lógica organizacional das empresas pesa de maneira contundente.

Estas relações e hierarquias não anulam as outras baseadas no tamanho das cidades, na rede de transportes, no comércio e nos serviços que afetam as populações residentes de forma desigual em razão de suas rendas. Consideramos, no entanto, que estas relações e hierarquias inspiradas na teoria dos lugares centrais de Christaller tornam-se menos imperativas diante do protagonismo que passa a ser exercido pelos fluxos e nexos estabelecidos pelas empresas dominantes, a partir da forma como elas utilizam o território, envolvendo a cidade e o campo numa trama de relações cujos nós estão alhures, no país e no mundo. 
Mapa 03. Área de atuação e sedes da Central Frimesa e de suas coproprietárias

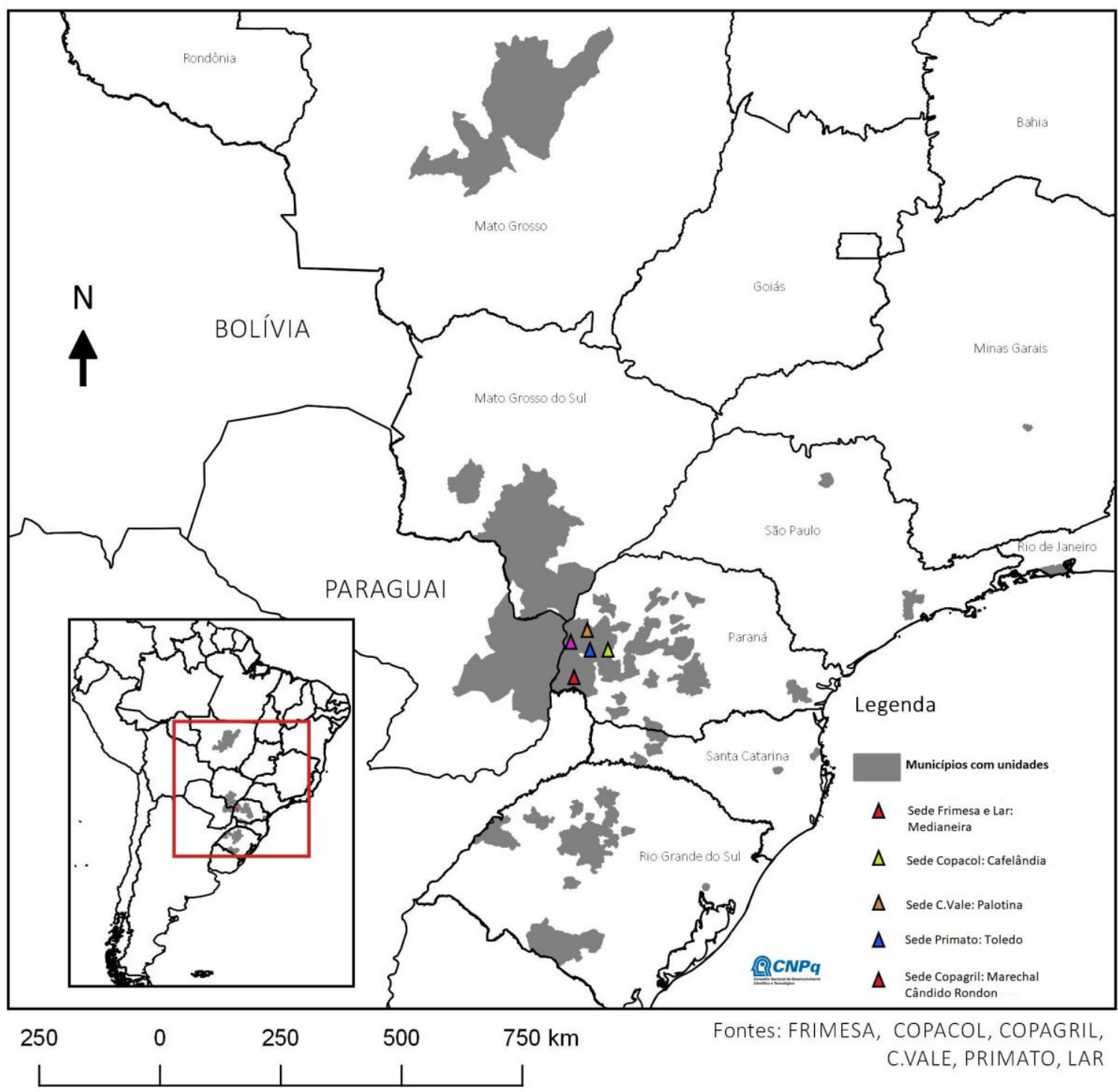

Jacques Boudeville (1973) já nos alertou para o fato do modelo de Christaller ser negligente em relação aos fluxos materiais e imateriais, assimétricos e dissimétricos gerados pela produção industrial, aos quais acrescentamos aqueles fluxos gerados pela moderna agroindústria. Considerando que no atual período histórico as grandes empresas exercem significativo poder no uso produtivo e no comando político do território, tomamos o partido de que a hierarquia urbana, é definida pelos fluxos imateriais (SANTOS,1994a, 1994b; SILVEIRA, 2010, p.82), próprios dos círculos de cooperação que coordenam os circuitos espaciais produtivos. Esta centralidade dos fluxos imateriais deve-se ao fato de o poder de controle sobre a economia e o espaço estar cada vez mais assentado na manipulação da informação (DIAS, 2008, p. 136), que se dá a partir de determinados lugares e segundo fluxos 
financeiros, de gestão e controle que as grandes empresas impõem através de sua estrutura hierárquica, definindo assim o essencial de sua influência (BOUDEVILLE, idem, p. 8) sobre suas unidades de produção, mas também sobre outras empresas, atividades e lugares.

A estrutura organizacional e a divisão territorial do trabalho das cooperativas analisadas são reveladoras dessa assertiva. Cafelândia, Marechal Cândido Rondon, Medianeira, Palotina e Toledo são lócus de tomadas de decisões estratégicas de médio e longo prazo, estando posicionadas no topo da hierarquia estabelecida pelas cooperativas que coordenam a vasta área demarcada no mapa 3 (acima). Nelas, estão abrigados a direção executiva e os conselhos administrativos e fiscal, que tomam as decisões centrais referendadas pelas assembleias de cooperados realizadas nestas mesmas sedes. Também estão localizados o comando das operações de logística, marketing, compra e venda e operações financeiras, laboratórios de análises biológicas, centros de pesquisa e inovação, além de formação de trabalhadores.

Abaixo deles, estão os municípios selecionados para a instalação de plantas industriais e unidades produtoras a montante e a jusante da produção agropecuária. Municípios escolhidos para abrigar, respectivamente, fábricas de sementes e rações, unidades produtoras de pintainhos, ovos de compostura, leitões e bezerros, que serão entregues aos seus produtores associados e plantas industriais que produzem cortes de carne, embutidos e pratos prontos, leite e derivados. São municípios diretamente integrados à rede agroindustrial demandantes de mão de obra assalariada de diferentes níveis de qualificação, desde os operacionais, passando pelos tecnólogos, pelos administrativos, de gerenciamento e gestão. São importantes nós cujos fixos recebem e geram parcela significativa dos fluxos materiais e imateriais mobilizados pelos circuitos espaciais de produção e pelos círculos de cooperação envolvidos na totalidade de rede produtiva agroindustrial.

Em um grande número de cidades de pequeno porte que sediam os municípios que formam a grande área demarcada no mapa 3, estão instaladas unidades que se situam na linha de frente da relação entre cooperativas e associados, centros de atendimento aos cooperados, pelos quais os produtores rurais têm acesso a semestres, fertilizantes, rações, agrotóxicos, assistência técnica, financiamento e seguro e por onde negociam sua produção. É a partir destas unidades que as cooperativas garantem sua atuação nos espaços agrícolas em extensa porção do território brasileiro e paraguaio, onde implantam a racionalização do espaço por meio dos pacotes tecnológicos, métodos de produção e parâmetros de qualidade, rentabilidade e custo necessários para que as mesmas se posicionem competitivamente no mercado. Esta atuação das cooperativas transborda para as outras atividades econômicas, empresas e 
sociedade. Vejamos alguns exemplos. A imposição de pacotes tecnológicos e a comercialização de fertilizantes, agrotóxicos e sementes fazem das cooperativas parceiros estratégicos da Monsanto, Syngenta, Dupont e Bayer, viabilizando a difusão regional do consumo dos produtos destas empresas. A necessidade de investir na instalação de aviários, máquinas e equipamentos agrícolas acaba também por definir as topologias e estratégias de empresas do setor na região, bem como dos bancos que atuam no mercado de crédito rural como o Banco do Brasil e as cooperativas de crédito como Sicred e Sicoob. Institutos e universidades públicas e privadas instalados nas cidades da região são mobilizados para a realização de pesquisas e formação de profissionais qualificados para o agronegócio. Como já observado, as cidades escolhidas para abrigar suas unidades de produção mudam o perfil do emprego e da renda e, logo, também do consumo que se moderniza.

A partir de pequenos centros urbanos do Oeste Paranaense, as empresas podem coordenar grande parcela do processo produtivo regional, e o fazem, ainda que sob o império de mercados distantes, e estabelecem, dessa forma, múltiplas interações com diferentes lugares do país e do mundo. Como podemos observar, há uma imbricada relação entre produtores cooperados e agroindústria e entre campo e cidade conduzida pela gestão das empresas cooperativas. As cidades do Oeste Paranaense conformam-se como cidades do campo, cidades do agronegócio que por meio de seus comércios e serviços produtivos, atendem as demandas das redes agroindustriais. Fato que, à luz da proposta de definição de tipos ideias de pequenas cidades de Roberto Lobato Corrêa (2011, p. 11), as classificaria como um "pequeno lugar central de uma hinterlândia agrária moderna, capitalista". Mas aquelas onde estão as sedes das cooperativas também abrigam a função de comando político e financeiro que coordenam fluxos materiais e imateriais que vão bastante além das referidas hinterlândias. Na medida em que abrigam atividades ordenadoras da produção e de seus fluxos, compreendemos essas cidades como espaços do mandar, ainda que se trate do exercício de uma regulação delegada (SANTOS e SILVEIRA, idem, p.268), obediente aos mercados distantes.

Em suma, temos no Oeste Paranaense um intenso processo de urbanização corporativa conduzida em conformidade com os avanços do agronegócio. Uma urbanização intimamente vinculada à expansão da agricultura e pecuária científica globalizada que constitui uma complexa trama de relações regionais articulada aos fluxos de mercadorias, dinheiro e informação que se dão segundo contextos estendidos que integram grande parte do território nacional e um vasto mercado internacional nos circuitos espaciais de produção de cada bem produzido. Como a divisão social e territorial do trabalho das empresas torna as interações 
espaciais mais intensas, estes centros passam a abrigar funções mais complexas e "a combinar interações que se realizam em escala local e regional com aquelas que se fazem a longa distância" (CORRÊA, 2001, p.429)

\section{Considerações finais: sobre a existência de cidades intermediárias de pequeno porte}

As ações das cooperativas analisadas, a partir das cidades de pequeno porte, demonstra a maior complexidade das relações interurbanas e entre cidade e campo que se delineiam no Oeste Paranaense no presente. Estas cidades são lugares onde se realiza a materialização das condições gerais de reprodução do agronegócio (ELIAS, 2008, p. 5) que abrigam a gestão, o controle e a tomada de decisões corporativas, participando de forma contundente da organização de vastas extensões do espaço geográfico. Apenas a coordenação da produção agroindustrial de carne suína e derivados de leite, que são uma parte dos negócios das cooperativas analisadas, já nos dá uma amostra desse fato (mapa 4).

Essas cidades também se constituem como lugares de abrigo, estratégia e resistência dos capitais regionais na disputa pelo uso do território entre cooperativas regionais e empresas globais do agro processamento. No Oeste Paranaense, também atuam grandes grupos como a Dairy Partnes América - DPA, joint venture formada pela Nestlé e a cooperativa neozelandesa Fonterra que, desde 2013, mantém um posto de captação e resfriamento de leite em Cascavel e a multinacional brasileira Brasil Foods S.A - BRF, maior produtora mundial de frango, que possui planta industrial na cidade de Toledo. Diferentemente das cooperativas analisadas, as sedes destas grandes corporações globais estão fora do Oeste Paranaense, impondo à região sua integração ainda mais alienada a uma solidariedade organizacional que a torna apenas um espaço do fazer. 
Mapa 04. Área de atuação da produção suína e leiteira da Frimesa e suas sedes de comando
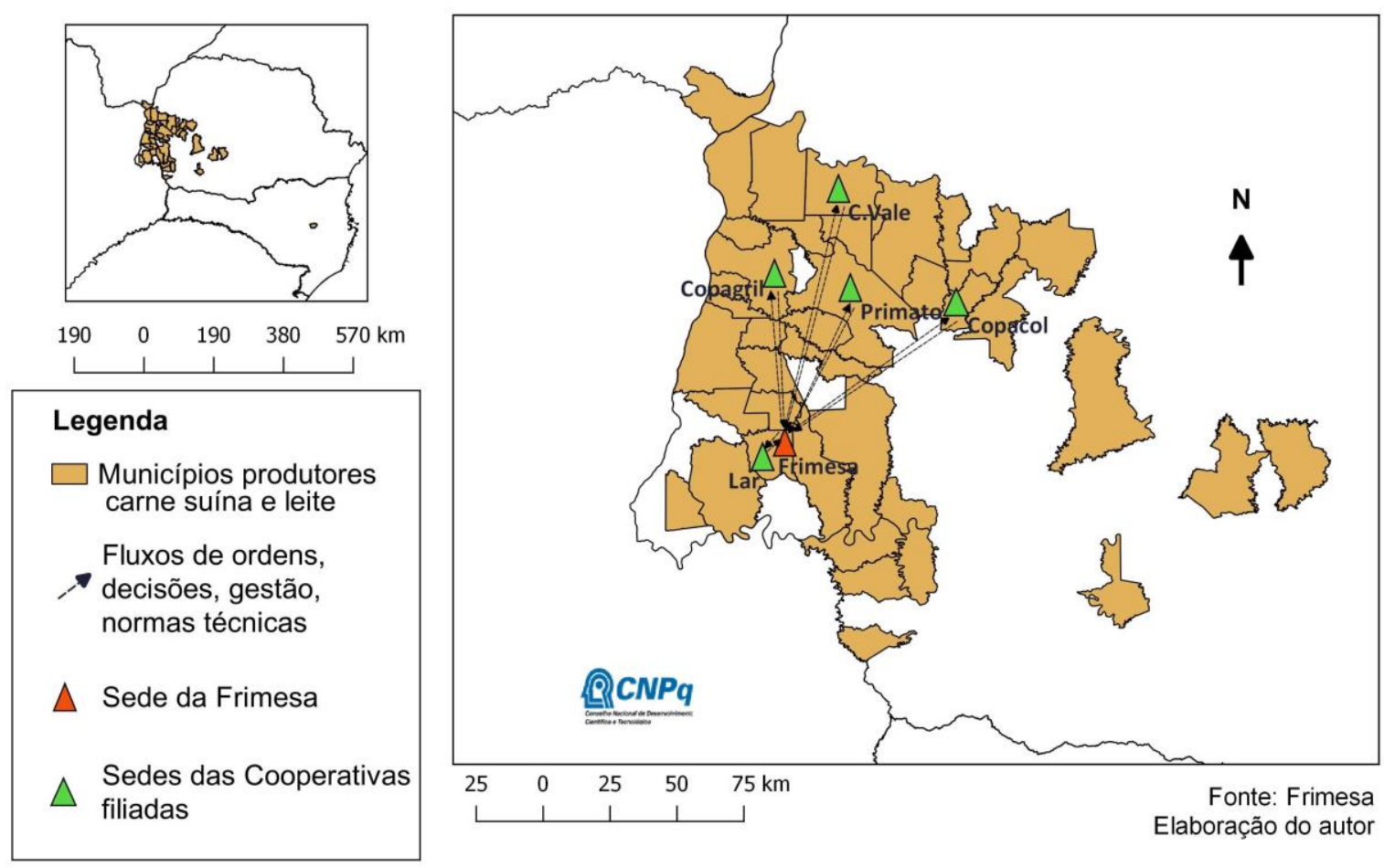

Retomemos aqui, o problema levantado por Tânia Fresca. Para esta autora (FRESCA, 2010, p. 79), as cidades do campo, na medida em que incorporam uma maior complexidade de atividades urbanas que não se restringem ao atendimento das necessidades vitais mínimas da população já não seriam cidades locais. Consideramos que as topologias e os circuitos espaciais produtivos e círculos de cooperação das empresas instaladas nas cidades do Oeste Paranaense corroboram com a afirmação dessa autora. Sob a perspectiva dos fluxos produtivos, aqueles aos quais Jacques Boudeville indica também serem importantes serem considerados e dos fluxos associados ao comando do processo produtivo, as cidades que abrigam as sedes dessas empresas apresentam uma mais diversificada integração na rede urbana brasileira, bem como uma área de influência que extrapola sua hinterlândia, sendo inseridas numa complexa teia de relações produtivas. No entanto, diferentemente da autora, também consideramos impreciso defini-las como pequenas cidades para diferenciá-las das cidades locais. Diante do imbróglio, aparentemente insolúvel, entre a perspectiva quantitativa e qualitativa na abordagem da rede e hierarquia urbanas, como já discutido neste artigo, consideramos que os parâmetros qualitativos são os mais seguros para compreendermos as funções exercidas pelas cidades na divisão territorial do trabalho, sem negligenciar o fato de o 
tamanho das cidades, que é relativo aos contextos do período e da região nos quais estão inseridas, continuar influenciando na localização de comércios e serviços mais sofisticados.

A partir de nossas análises, propomos que as cidades do Oeste Paranaense que sediam as cooperativas agroindustriais, na medida em que abrigam importante parcela do comando produtivo com significativo alcance territorial, apresentam uma interessante singularidade, pois conformam cidades intermediárias de pequeno porte, cuja dimensão populacional não as impede de realizar as mediações características deste tipo de cidade, nem de assumir funções mais complexas na rede urbana que, frequentemente, corresponde às cidades médias consideradas aquelas acima de 100 mil habitantes (SANTOS, 1994a, p.73).

As cidades de pequeno porte do Oeste Paranaense que sediam as cooperativas agroindustriais são lugares a partir dos quais estas empresas comandam e organizam extensas parcelas produtivas do território, mediando a relação entre a região e as demandas de qualidade e custo ditadas pelos mercados nacional e internacional e influenciando em políticas públicas, como a pavimentação de estradas vicinais necessária para conferir fluidez na logística de abastecimento dos frigoríficos e laticínios ou a doação de terrenos, isenções ficais e dotação de infraestruturas de energia e saneamento necessárias para a instalação de plantas produtivas. Essas cidades se constituem, portanto, como "uma ponte entre o global e o local, em vista das crescentes necessidades de intermediação e da demanda também crescente de relações" (SANTOS e SILVEIRA, 2001, p.281) da região onde estão localizadas. Elas são os lócus onde as informações e determinações de mercado oriundas do país e do mundo são traduzidas de forma a viabilizar a concretização da adequação da região às necessidades demandas pela divisão do trabalho que se impõe no presente.

É importante registrar que os circuitos espaciais produtivos e círculos de cooperação das empresas analisadas demonstram não haver demandas significativas por parte delas que sejam atendidas pela cidade de Cascavel, maior cidade da região e considerada pelo IBGE àquela que comanda o campo no Oeste Paranaense. Embora seja uma cidade de maior porte e mais complexa, agregando um maior número de comércios e serviços, Cascavel, que também é sede de três das treze cooperativas regionais, no que diz respeito ao comando do processo produtivo regional, que é o que está em questão nesta análise, não está sozinha. Ela divide esta função com as cidades de menor porte analisadas.

Frisamos, no entanto, que a formação dessas cidades intermediárias de pequeno porte trata de uma especificidade da forma como se dá a expansão do meio técnico-científicoinformacional no Oeste Paranaense. Região na qual a expansão deste meio ocorre associada à agropecuária científica globalizada que se impõe com intensa participação de cooperativas 
agroindustriais, cuja origem está intimamente relacionada ao processo de ocupação e povoamento desta região por colonos gaúchos e catarinenses desde meados do século $\mathrm{XX}$, bem como à forma específica como a mesma foi sendo integrada à divisão territorial e internacional do trabalho, levando à constituição de arranjos territoriais produtivos especializados na cadeia de proteínas. Entendemos que a análise aqui apresentada é uma pequena amostra da diversidade do processo de modernização e compartimentação do território brasileiro a serviço do processo de acumulação do capital, bem como da atual complexidade da rede urbana.

Aproveitamos a ocasião para agradecer ao $\mathrm{CNPq}$ pelo auxílio à pesquisa que viabilizou as reflexões aqui apresentadas.

\section{Bibliografia}

ABREU, M. O estudo geográfico da cidade no Brasil: evolução e avaliação. Contribuição à História do Pensamento Geográfico Brasileiro. Revista Brasileira de Geografia, v.56, n.1/4, p. 21-122, jan./jun. 1994.

BESSA, K. Estudos sobre a rede urbana: os precursores da teoria das localidades centrais. GeoTextos, v. 8, n.1, p. 147-165, jul. 2012)

BOUDEVILLE, J. Desenvolvimento polarizado e planejamento regional. Boletim Geográfico, Rio de Janeiro, 32 (237), p. 5-15, nov./dez., 1973.

CANTARIN, F. Estudos de redes urbanas no Brasil: reflexões sobre transformações metodológicas. Revista Paranaense de Desenvolvimento, Curitiba, v. 36, n.129, p. 117-133, jul./dez. 2015.

CATAIA, M. A.; RIBEIRO, L. H. L. Análise de situações geográficas: notas sobre metodologia e pesquisa em geografia. Revista da Associação Nacional de Pós-Graduação e Pesquisa em Geografia (Anpege). p. 9-30, V. 11, n. 15, jan.-jun. 2015.

CASTILLO, R. e FREDERICO, S. Espaço geográfico, produção e movimento: uma reflexão sobre o conceito de circuito espacial produtivo. Sociedade \& Natureza, Uberlândia, 22 (3), p. 461-474, dez. 2010a.

CASTILlO, R. e FREDERICO, S. Dinâmica Regional e Globalização: espaços competitivos agrícolas no território brasileiro. Mercator, Fortaleza, v. 9, n. 18 jan./abr. P, 17-26, 2010b.

CASTRO. A. C. e CASTRO, L. B. (orgas.) Do desenvolvimento renegado ao desafio sinocêntrico: reflexões de Antônio Barros de Castro sobre o Brasil. Rio de Janeiro: Elsevier, 2012.

CIRADINI, O. L.; FREDERICQ, A. Agricultura, cooperativas e multinacionais. Rio de Janeiro: Centro Edeistein de Pesquisas Sociais, 2009;

CONTE, C. H. Rede urbana: uma breve abordagem teórica. GeoAtos, Presidente Prudente, n.14, v.1, p. 76-93, jan./jun. 2014.

CORRÊA, R. L. Hinterlândias, hierarquias e redes: uma avaliação da produção geográfica brasileira, Revista Brasileira de Geografia, Rio de Janeiro, 51(3), p. 113-137, 1989.

CORRÊA, R. L. Globalização e reestruturação da rede urbana - uma nota sobre as pequenas cidades. Revista Território, Rio de Janeiro, ano IV, n. 6, p. 43-53, jan./jun. 1999.

CORRÊA, R. L. Reflexões sobre a dinâmica recente da rede urbana brasileira. Anais do IX Encontro Nacional da ANPUR, vol. 3, p. 424-430, 2001. 
CORREAA, R. L. As pequenas cidades na confluência do urbano e do rural. GEOUSP Espaço e Tempo, São Paulo, n. 30, p. 05-12, 2011.

DIAS, L. C. Redes eletrônicas e novas dinâmicas do território brasileiro. In CASTRO, Iná Elias de, GOMES, Paulo César., CORRÊA, Roberto Lobato (orgs.). Brasil: questões atuais da reorganização do território. Rio de Janeiro: Bertrand Brasil, 2008.

EGLER, C.; MENDES, C. C.; FURTADO, B. A.; PEREIRA, R. H. M. Bases conceituais da rede urbana brasileira: análise dos estudos de referência. In PEREIRA, R. H. M. e FURTADO, B. A. (orgs.) Dinâmica urbano-regional: rede urbana e suas interfaces. Brasília: Ipea, p. 24-46, 2011.

ELIAS, D. Relações campo-cidade, reestruturação urbana e regional no Brasil. XII Coloquio Internacional de Geocrítica, p 1-15. 2012.

ELIAS, D. Ensaios sobre os espaços agrícolas de exclusão. Revista NERA (UNESP), Presidente Prudente -SP, v. 1, n.8, p. 29-51, 2006.

ELIAS, D. Redes agroindustriais e urbanização dispersa no Brasil. Diez años de cambios en el Mundo, en la Geografía y en las Ciencias Sociales, 1999-2008. Actas del X Coloquio Internacional de Geocrítica, Universidad de Barcelona, 26-30 de mayo de 2008. $<$ http://www.ub.es/geocrit/-xcol/270.htm>

ENDLICH, A. M. O estudo das pequenas cidades e os desafios conceituais: áreas de comparabilidade e complexidade. Hoelas, n. 15, p. 149-165, 2011.

FAJARDO, S. O novo padrão de desenvolvimento agroindustrial e a atuação das cooperativas agroindustriais no Paraná. Revista $R^{\prime} E$ GA, Curitiba, n. 11, p.89-102, 2006;

FERREIRA, M. A. M.; BRAGA, M. J. Diversificação e Competitividade nas Cooperativas Agropecuárias. $R A C$, Curitiba, v.8, n. 4, out./dez. p. 33-55, 2004.

FRESCA, T. M. Em defesa dos estudos das cidades pequenas no ensino de geografia. Geografia, Londrina, v. 10, n.1, p. 27-34, jan./jun. 2001.

FRESCA, T. M. Centros locais e pequenas cidades: diferenças necessárias. Mercator, número especial, p. 75-81, dez. 2010.

GEIGER, P. P. e DAVIDOVICH, F. Aspectos do fato urbano no Brasil. Revista Brasileira de Geografia, ano XXIII, n.2, p. 3-102, abr.-jun. 1961.

IPARDES, Oeste Paranaense: ${ }^{\circ}$ espaço relevante: especificidades. Curitiba: Ipardes, 2008.

MARX, K.; ENGELS, F. A ideologia alemã. Rio de Janeiro: Civilização Brasileira, 2007.

MAZZALI, L. O processo recente de reorganização agroindustrial: do complexo à organização "em rede". São Paulo: Editora UNESP, 2000.

MONBEIG, P. O estudo geográfico das cidades. Revista do Arquivo Municipal. [de] São Paulo, v. 7, n.73, 1941. Transcrito em: Boletim Geográfico, v. 1, n.7, p 7-29, 1943.

MELO, N. A. e SOARES, B. R. Pequenas cidades: seus atributos, dilemas e cotidiano no contexto espacial da microrregião geográfica de Catalão - GO, In: XII Encontro de Geógrafos da América Latina, Montevideo. 2009.

MOURA, R. e WERNECK, D. Z. Rede, hierarquia e região de influência das cidades: um foco sobre a Região Sul. Revista Paranaense de Desenvolvimento, Curitiba, n. 100, p. 27-57, jan./jun., 2001.

OLANDA, E. R. As pequenas cidades e o vislumbrar do urbano pouco conhecido pela geografia. Ateliê Geográfico, Goiânia - GO, v.2 n.2, agos., p. 83-191, 2008.

OLIVEIRA, B. S. e SOARES, B. R. Cidade locais do Triângulo Mineiro e Alto Paranaíba/MG: algumas considerações. Caminhos da Geografia, 3(5), p.52-72, 2002.

PIQUET, R. Indústria e Território no Brasil Contemporâneo. Rio de Janeiro: Garamond, 2007.

REFFESTIN, C. Por uma geografia do poder. São Paulo: Ática, 1993.

RIBEIRO, A. C. Teorias da Ação. Rio de Janeiro: Letra Capital, 2014.

ROCHEFORT, M. Métodos de estudos das redes urbanas. Boletim Geográfico - IBGE, Rio 
de Janeiro, ano XIX, n. 160, p. 3-18, 1961.

SANTOS, M. A Cidade como centro de região: definições e métodos de avaliação da centralidade. UFBA, Laboratório de Geomorfologia e Estudos Regionais, 1959.

SANTOS, M. A urbanização brasileira. São Paulo: Hucitec, 1994a.

SANTOS, M. Técnica, espaço, tempo. Globalização e meio técnico-científico informacional. São Paulo: Hucitec. 1994b.

SANTOS, M. A natureza do espaço: técnica e tempo, razão e emoção, São Paulo: Hucitec, 1996a.

SANTOS, M. O trabalho do geógrafo no terceiro mundo. São Paulo: Hucitec, 1996b.

SANTOS, M. Da totalidade ao lugar. São Paulo: Edusp, 2005.

SANTOS, M. e SILVEIRA, M. L. O Brasil: território e sociedade no início do século XXI. Rio de Janeiro - São Paulo: Record, 2001.

SILVEIRA, M. L. Uma situação geográfica: do método à metodologia. Revista Território, ano IV, n. 6, jan.- jun., p.21-28, 1999.

SILVEIRA, M. L. Região e Globalização: pensando um esquema de análise. Redes, Santa Cruz do Sul, v. 15, n.1, p. 74-88, jan./abr. 2010.

SPOSITO, M. E. B. Novas redes urbanas: cidades médias e pequenas no processo de globalização. Geografia, Rio Claro, v. 35, n.1, p.51-62, jan./abr. 2010.

ZYLBERSZTAJN, D. Organização de cooperativas: desafios e tendências. Revista de Administração, São Paulo. v. 29, n.3, p. 23-32, jul./set. 1994.

Recebido em 29 de março de 2018.

Aceito em 03 de maio de 2018. 